\title{
The "Waterbed" Effect and Price Regulation
}

\author{
AARON SCHIFF * \\ Department of Economics, University of Auckland
}

\begin{abstract}
This paper investigates conditions that generate the so-called "waterbed" effect under price regulation. This is the effect whereby regulation of one price of a multiproduct firm causes one or more of its unregulated prices to change as a result of the firm's profit-maximizing behavior. A waterbed effect is shown to arise when demands and/or marginal costs are interdependent, firms use nonlinear pricing, or there is a zero-profit constraint or global price cap. Some implications for market definition, welfare analysis of regulation, non-price competition, collusion and two-sided markets are also discussed, as well as specific applications to fixed-to-mobile termination and bank overcharges.
\end{abstract}

\section{Introduction}

This paper considers the conditions under which regulation of one of the prices charged by a multiproduct firm will result in a change of the firm's other unregulated price(s). This has become known as the "waterbed" effect: pressing down on one part of the bed causes another part to rise. However, this hydraulic analogy is potentially misleading for two reasons. First, it implies the existence of some sort of constraint, as it is only the physical constraint of the bag containing the water that causes the effect with a real bed. Instead, economic waterbed effects can arise as a natural result of unconstrained profitmaximization, as well as the presence of constraints. Second, it is possible that downwards regulation of one price of a multiproduct firm will cause its other price(s) to also fall rather than rise. In spite of these deficiencies, the term 'waterbed' effect will be used in this paper, because it is convenient and has become accepted terminology.

Understanding the causes and implications of a waterbed effect is particularly important in network industries for two main reasons: (i) Firms in these industries are typically multiproduct firms, and (ii) Network industries are often the target of price regulation due to economies of scale and natural monopoly market structures. Accordingly, this paper has two main aims. The first is to make clear the conditions under which a waterbed effect arises. The second objective is to discuss the implications of the existence of a waterbed effect for practical aspects of regulation. Issues relating to market definition, welfare analysis of regulation, non-price competition, collusion and regulation of two-

\footnotetext{
* Department of Economics, University of Auckland, Private Bag 92019, Auckland, New Zealand. E-mail: a.schiff@auckland.ac.nz I thank an anonymous referee, Paolo Siciliani, John Small, Doug Watt and especially the editor Julian Wright for helpful comments and suggestions.
} 
sided markets will be discussed, as well as specific applications to termination of fixed-line calls in mobile telephony and bank overcharge fees.

In terms of the first objective, it will be shown that a waterbed effect results as a natural outcome of profit-maximizing behavior by firms under a range of conditions. The most general requirement is that the marginal revenue and/or marginal cost of the unregulated product(s) must depend on the price or quantity of the regulated product. This means that the argument sometimes advanced by firms of "if you take revenue from somewhere we must make it up somewhere else" is not valid unless firms have fixed and common costs and compete under conditions of free entry and exit, or if a firm is subject to an additional regulation of a global price cap that leads to "Ramsey" pricing. In other words, if the demands and costs of the regulated and unregulated products are independent in that the price of the regulated product does not affect marginal revenues or marginal costs of the unregulated products, then rational firms will not typically change unregulated prices no matter how severe the regulation is. The exception with demand and cost independence is if regulation results in the firms being unable to cover fixed costs and some firms leave the industry, reducing the intensity of competition and allowing unregulated prices to rise, or if a firm subject to a global price cap rebalances its prices.

Regulation of termination rates for fixed-to-mobile calls is a specific example of a situation where a waterbed effect is expected to exist. These are fees charged by mobile telephony firms to fixed-line firms for the completion (termination) of calls from fixed-line customers to mobile customers. ${ }^{2}$ Mobile firms are multiproduct firms, in that they sell mobile services to mobile customers, and mobile termination services to fixed-line firms, among other things. For various reasons, telecommunications regulators around the world have argued that market-based mobile termination rates are too high and have proposed regulated cuts in these rates. In some regulatory investigations, there has been considerable debate about whether this will cause mobile operators to raise prices charged to mobile customers or reduce subsidies for handsets (or both). If such effects occur then mobile subscribers would be made worse off, and these detriments would offset any potential benefits of regulation.

To give another example, a 2006 report by the consultancy PriceWaterhouseCoopers claimed that downwards regulation of various fees in the credit card industry in the UK would lead to a waterbed effect and other unregulated fees would increase as a result. ${ }^{3} \mathrm{~A}$ similar claim was made in response to the investigation by the UK's Office of Fair Trading into the penalty charges levied by banks on customers who overdrew their accounts without prior authorization. ${ }^{4}$ Regulation of penalty fees for unauthorized overdrafts is examined in section 3.5.

As will be discussed, the existence of a waterbed effect has a number of important practical implications for regulation. For example, market definition analysis that ignores the linkages between prices implied by a waterbed effect is likely to be erroneous. Second, any quantitative analysis of the welfare effects of price regulation that only considers the regulated product and ignores effects on other products through the waterbed effect may lead to suboptimal decisions to accept or reject proposed regulations. Third, these waterbed

\footnotetext{
${ }^{2}$ See Wright (2002), Armstrong (2002) and Armstrong and Wright (2008) for a detailed analysis of mobile termination.

${ }^{3}$ Precious Plastic 2007 - Consumer credit in the UK. Available at www.pwc.com/extweb/pwcpublications.nsf/docid/315457B0346CB45E8025722100585864

4 "Squash some bank charges and others rise up in their place," The Independent on Sunday, 8 October 2006.
} 
effects may not be confined only to prices, and may affect other dimensions of competition such as quality and product variety. Waterbed effects are also fundamental characteristics of 'two-sided' markets and cannot be ignored in any regulation of such markets.

The organization of the rest of this paper is as follows. Section 2 examines the causes of a waterbed effect in terms of firm and market characteristics. Section 3 then discusses the implications of this for regulation and examines the examples of fixed-to-mobile termination, bank overcharges and two-sided markets, as well as the issue of how to measure the size of a waterbed effect. Section 4 offers concluding remarks.

\section{Causes of the waterbed effect}

To illustrate the factors that can cause a waterbed effect, it is sufficient to consider firms that produce two products, A and B, though the basic conclusions hold more generally. The first two subsections below consider the conditions under which downwards regulation of the price of good B causes a change in the price of good A. The final subsection considers nonlinear pricing of a single good.

\subsection{Demand and cost interdependence}

First suppose that good A and B are supplied by a monopoly, with prices $p_{A}$ and $p_{B}$, and quantities $q_{A}$ and $q_{B}$. Assuming that the firm sets prices, a general expression for its profit is

$$
\pi\left(p_{A}, p_{B}\right)=p_{A} q_{A}\left(p_{A}, p_{B}\right)+p_{B} q_{B}\left(p_{B}, p_{A}\right)-C\left(q_{A}\left(p_{A}, p_{B}\right), q_{B}\left(p_{B}, p_{A}\right)\right)
$$

where $q_{A}(\cdot)$ and $q_{B}(\cdot)$ are the demands that the firm faces and $C(\cdot)$ is its total cost function. This profit function allows for the possibilities that the demand for each good may depend on the price of the other good, and that the marginal cost of producing each good could depend on the quantity of the other produced.

In this context, suppose that the unregulated profit-maximizing prices are $\tilde{p}_{A}$ and $\tilde{p}_{B}$. Then suppose the price of good $\mathrm{B}$ is regulated to $p_{B}^{R}<\tilde{p}_{B}$. Under some regularity conditions, at an interior solution the profit-maximizing price for the unregulated good $\mathrm{A}$ is given by the solution to the first-order condition $\partial \pi / \partial p_{A}=0$. Implicit differentiation gives the change in $p_{A}$ with respect to a regulated change in $p_{B}$ as:

(1) $\frac{d p_{A}}{d p_{B}}=-\frac{\partial^{2} \pi\left(p_{A}, p_{B}\right)}{\partial p_{A} \partial p_{B}} \div \frac{\partial^{2} \pi\left(p_{A}, p_{B}\right)}{\partial p_{A}^{2}}$.

The denominator of (1) is negative by the second-order condition for the profit maximizing choice of $p_{A}$. Therefore, a waterbed effect exists under monopoly if the cross- 
partial derivative $\partial^{2} \pi\left(p_{A}, p_{B}\right) / \partial p_{A} \partial p_{B}$ is non-zero. ${ }^{5}$ This occurs if the marginal revenue and/or marginal cost of good A depend on the price of good B. In addition, the sign of $d p_{A} / d p_{B}$ is the same as the sign of the effect of a marginal change in $p_{B}$ on the marginal profitability of $p_{A}$.

Under oligopoly, it need not be the case that the cross-partial derivative of the marginal profitability of the price of good A with respect to a firm's own price for good B be nonzero to generate a waterbed effect. To illustrate, suppose there are $N$ firms in both markets. Firm $i$ 's profit is $\pi_{i}\left(p_{A 1}, p_{A 2}, \ldots, p_{A N}, p_{B 1}, p_{B 2}, \ldots, p_{B N}\right)$ where $p_{A i}$ and $p_{B i}$ are the prices of firm $i$ in the two markets. Suppose firms compete in the market for good A while the price of $\mathrm{B}$ is regulated to $p_{B}$ for all firms. Then, assuming an interior equilibrium, the equilibrium prices for $\mathrm{A}$ are determined by the solution to the first-order conditions $\partial \pi_{i} / \partial p_{A i}=0$ for $i=1,2, \ldots, N$. Suppose for simplicity the firms are symmetric and the equilibrium price of good $\mathrm{A}$ is $p_{A}\left(p_{B}\right)$ for all firms. Then from the first-order condition for firm $i$ we obtain

$$
\frac{d p_{A}}{d p_{B}}=-\frac{\sum_{k=1}^{N} \frac{\partial^{2} \pi_{i}}{\partial p_{A i} \partial p_{B k}}}{\frac{\partial^{2} \pi_{i}}{\partial p_{A i}^{2}}+\sum_{j=1}^{N} \frac{\partial^{2} \pi_{i}}{\partial p_{A i} \partial p_{A j}}} \text { for } j \neq i \text {. }
$$

Regularity conditions for the existence and stability of equilibrium plus the assumption that prices are strategic complements ensure the denominator is negative. A waterbed effect will exist provided that $\partial^{2} \pi_{i} / \partial p_{A i} \partial p_{B k}$ is non-zero for some $k$. Thus, as long as there is some effect of a change in $p_{B}$ on the marginal profitability of good $\mathrm{A}$, it will flow through into equilibrium prices. ${ }^{6}$ More generally, a waterbed effect will exist if the marginal revenue or marginal cost of good A for at least one firm depends on the price of good B set by either that firm or at least one other firm.

The size of any waterbed effect will differ under oligopoly compared to monopoly. However, in general it is not possible to make unambiguous predictions regarding the relative sizes of the effect under competition compared to monopoly, as it depends on the characteristics of demand in the market. To illustrate, suppose that downwards regulation of the price of good B results in an increase in the marginal cost of good A due to diseconomies of scope. If firms are perfectly competitive then the price of good A must increase one-for-one with the increase in its marginal cost. However, under monopoly the rate of "pass-through" to the price of good A will depend on the characteristics of demand.

\footnotetext{
${ }^{5}$ In general, it is possible that $\partial^{2} \pi\left(p_{A}, p_{B}\right) / \partial p_{A} \partial p_{B}<0$, hence the price of good A also falls if the price of good $\mathrm{B}$ is regulated downwards, for example, if there are economies of scope. The physical waterbed analogy is therefore not suitable in this case.

${ }^{6}$ An example case of these conditions is where the oligopoly game is "smooth supermodular" (Vives, 2005) with $\partial^{2} \pi_{i} / \partial p_{i k} \partial p_{j k} \geq 0$ for $i \neq j$ and $\partial^{2} \pi_{i} / \partial p_{i k} \partial p_{j l} \geq 0$ for $k \neq l$ and all $i, j$ where $p_{i k}$ is the price of good $i$ set by firm $k$.
} 
It is straightforward to show that the rate of pass-through is one half if demand is linear, but the rate of pass-through exceeds one under constant-elasticity demand for example. ${ }^{7}$

It is also important to note that the existence of a waterbed effect does not depend on firms having market power. Under perfect competition, the equilibrium price of good A is not determined by the solution to a system of first-order conditions as above, but rather by the free-entry and price-taking assumptions. Nevertheless, as will be illustrated in the discussion of fixed-to-mobile termination in section 3.5 below, a waterbed effect can arise even if competition ensures that the firms that produce both products make zero profits, due to the nature of demand in the markets.

In general, the above discussion shows that a waterbed effect will exist if the marginal profitability of the unregulated good(s) depends on the price of the regulated good. In practice, this will occur if the demand for the unregulated good(s) depends on the price of the regulated good (if they are complements or substitutes), and/or if the marginal cost of the unregulated good(s) depends on the quantity (hence the price) of the regulated good (if there are economies or diseconomies of scope).

To illustrate demand interdependence, consider a monopoly for simplicity and to focus on the demand side suppose production requires constant marginal costs of $c_{A}$ and $c_{B}$. Then the monopolist's profit function can be written as

$$
\pi\left(p_{A}, p_{B}\right)=\left(p_{A}-c_{A}\right) q_{A}\left(p_{A}, p_{B}\right)+\left(p_{B}-c_{B}\right) q_{B}\left(p_{B}, p_{A}\right) .
$$

If $p_{B}$ is regulated then the profit-maximising price of $\mathrm{A}$ is determined by the firstorder condition $\partial \pi / \partial p_{A}=0$. Implicit differentiation gives

$$
\frac{d p_{A}}{d p_{B}}=-\frac{\frac{\partial q_{A}}{\partial p_{B}}+\frac{\partial q_{B}}{\partial p_{A}}+\left(p_{A}-c_{A}\right) \frac{\partial^{2} q_{A}}{\partial p_{A} \partial p_{B}}+\left(p_{B}-c_{B}\right) \frac{\partial^{2} q_{B}}{\partial p_{A} \partial p_{B}}}{2 \frac{\partial q_{A}}{\partial p_{A}}+\left(p_{A}-c_{A}\right) \frac{\partial^{2} q_{A}}{\partial p_{A}^{2}}+\left(p_{B}-c_{B}\right) \frac{\partial^{2} q_{B}}{\partial p_{A}^{2}}} .
$$

The denominator of this expression is negative by the second-order condition, but the numerator is difficult to interpret without making further assumptions about demand. In the case of linear demand, the cross-partials are zero, and so $d p_{A} / d p_{B}$ equals the ratio of the average sensitivity of each demand to change in the price of the other good, to the sensitivity of the demand for good $A$ to changes in its own price. For example, if $q_{i}\left(p_{i}, p_{j}\right)=a-b p_{i}+d p_{j}$ for $i, j=A, B$ then $d p_{A} / d p_{B}=d / b$. Thus, if the goods are substitutes $(d>0)$ and the price of good $B$ is regulated downwards then this reduces the demand for good A. A profit maximizing firm responds to this by reducing the price of good A. Similarly, if the goods are complements $(d<0)$ then a downwards regulation of the price of good $\mathrm{B}$ causes a rise in the profit-maximizing price of good A.

To illustrate cost interdependence, consider again a monopoly and now suppose that the demands for the two goods are independent but the marginal cost of either good

\footnotetext{
${ }^{7}$ See, for example, section 1.1.1.3 of Tirole (1988).
} 
depends on the quantity of the other good that is produced. In this case, a regulated reduction in the price of good $B$ will increase the quantity of it that is sold, which will affect the marginal cost of good A, hence its profit-maximising price. The monopolist's profit is

$$
\pi\left(p_{A}, p_{B}\right)=p_{A} q_{A}\left(p_{A}\right)+p_{B} q_{B}\left(p_{B}\right)-C\left(q_{A}\left(p_{A}\right), q_{B}\left(p_{B}\right)\right)
$$

Under regulation of $p_{B}$ the first-order condition $\partial \pi / \partial p_{A}=0$ again gives the profitmaximizing price $p_{A}\left(p_{B}\right)$. Totally differentiating with respect to $p_{B}$ gives

(2) $\frac{d p_{A}}{d p_{B}}=\frac{\frac{\partial^{2} C}{\partial q_{A} \partial q_{B}} q_{A}^{\prime} q_{B}^{\prime}}{\left(2-\frac{\partial^{2} C}{\partial q_{A}^{2}} q_{A}^{\prime}\right) q_{A}^{\prime}+\left(p_{A}-\frac{\partial C}{\partial q_{A}}\right) q_{A}^{\prime \prime}}$.

The second-order condition means that the denominator is negative. Since $q_{A}^{\prime}$ and $q_{B}^{\prime}$ are also both negative, this means that the sign of $d p_{A} / d p_{B}$ is the opposite of the sign of the effect of a change in $q_{B}$ on the marginal cost of good A, that is, the sign of $\partial^{2} C / \partial q_{A} \partial q_{B}$. This is intuitive: if an increase in the quantity of good $B$ sold increases the marginal cost of good A, then a regulated decrease in the price of good B will cause an increase in its quantity and a corresponding increase in the price of good A due to the higher marginal cost of good A. If, on the other hand, an increase in the quantity of good B reduces the marginal cost of good $\mathrm{A}$, then the waterbed effect works in the opposite direction and the price of good A falls in response to a regulated reduction in the price of good B.

If we also assume that demand is linear, then (2) simplifies to $d p_{A} / d p_{B}=\frac{1}{2} q_{B}^{\prime} \partial^{2} C / \partial q_{A} \partial q_{B}$. In this case under monopoly the rate at which the price of good $A$ changes in response to regulation equals half of the product of the change in the demand for good B and the effect of a change in the quantity of good B on the marginal cost of good A. However, the rate of "pass-through" depends on the properties of demand. If demand for good $\mathrm{A}$ is convex to the origin $\left(q_{A}^{\prime \prime}>0\right)$, then the denominator of (2) becomes smaller in absolute value compared to when demand is linear, hence the rate at which $p_{A}$ changes exceeds the rate attained when demand is linear. "Pass-through" is therefore greater the "more convex" is the demand for good 1 relative to the origin. ${ }^{8}$ As shown in Figure 1, a given decrease in price causes a larger increase in quantity demanded if demand is convex compared to linear. On the other hand, a given increase in price causes a larger decrease in quantity demanded if demand is linear, assuming the two demands have the same slope at the starting point. If, due to cost complementarities, regulation of the price of good B causes the price of good A to decrease, then the firm's incentive to decrease this price is greater when demand is more convex, since the increase in sales that it achieves as a result is greater. Similarly, if regulation causes the price of

\footnotetext{
${ }^{8}$ Similar results are derived by Hausman and Leonard (1999) in the context of pass-through of cost efficiencies of mergers to consumers.
} 
good A to increase then the incentive to increase this price is stronger when demand is more convex, since the reduction in the quantity of good A that is sold is smaller.

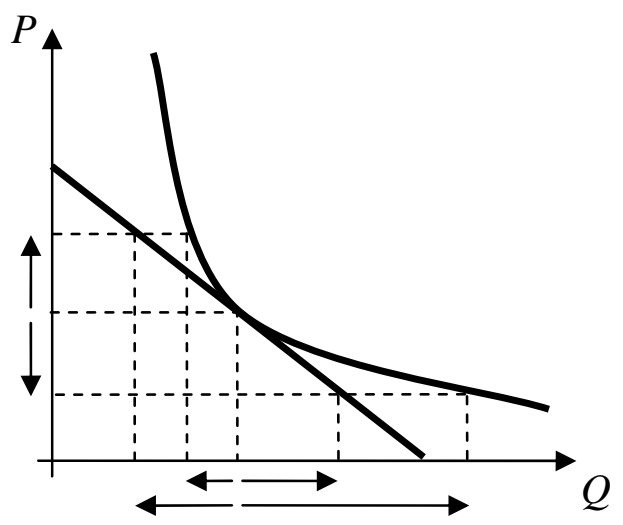

Figure 1: Change in quantity demanded for a given change in price under linear and convex demand.

\subsection{Competition with fixed and common costs}

To isolate the implications of fixed and common costs in a competitive market, suppose that the demands and variable costs for goods $\mathrm{A}$ and $\mathrm{B}$ are independent, but there is a common fixed cost of $f$ required for production of both goods. Also, assume for simplicity that there are no product-specific fixed costs. Suppose that $p_{A}^{*}$ and $p_{B}^{*}$ are the equilibrium prices and assume that free entry and exit in the markets for both goods simultaneously implies that $\pi_{i}\left(p_{A}^{*}, p_{B}^{*}\right)=0$ for each firm $i$. Under the assumptions of independence of the demands and variable costs, the marginal revenues and marginal costs of the two goods are independent. Thus, regulation of the price of good B has no direct impact on a firm's profit-maximizing choice of good A and we must investigate alternative channels by which the price of good A may change. One possibility with free entry and exit is that a regulated reduction in the price of good B causes a reduction in intensity of competition in the market for good A due to a reduction in the number of firms in the market. Downwards regulation of $p_{B}$ will cause existing firms to make losses at the prevailing equilibrium price $p_{A}^{*}$ which may cause some firms to exit the market, driving up the price of good A. ${ }^{9}$

To illustrate, consider the "circular city" model of Salop (1979). In this model, consumers are uniformly distributed around the perimeter of a unit circle and $N$ identical firms are uniformly spaced around the circle. The firms compete in prices and all consumers buy a single unit of a good from the firm that yields the highest net utility taking into account the firm's price and a "transportation cost" that depends on the distance from the consumer to the firm. Suppose that all $N$ firms compete in two independent circular cities that model the markets for goods $\mathrm{A}$ and $\mathrm{B}$. Let $t_{A}$ and $t_{B}$ be the "transportation cost" parameters that measure the degree of differentiation of the two

\footnotetext{
${ }^{9}$ See section 3.5 below for an illustration of how a waterbed effect can arise under perfect competition even when there are no fixed and common costs.
} 
products. Also assume that production requires constant marginal costs of $c_{A}$ and $c_{B}$ and a common fixed cost of $f$. Then it is straightforward to show ${ }^{10}$ that the equilibrium prices are

(3) $p_{i}^{*}=c_{i}+\frac{t_{i}}{N^{*}} \quad$ for $i=A, B$

where $N^{*}=\sqrt{\left(t_{A}+t_{B}\right) / f}$ is the equilibrium number of firms determined by the zero-profit constraint $\left[\left(p_{A}^{*}-c_{A}\right)+\left(p_{B}^{*}-c_{B}\right)\right] / N^{*}-f=0$.

Now suppose that the price of good $\mathrm{B}$ is regulated to $p_{B}^{R}$. Then the number of firms and the price of good A are jointly determined by (3) for $i=A$ and the zero-profit constraint. Solving simultaneously gives the price of good A and the number of firms in equilibrium under regulation as

$$
\begin{aligned}
& p_{A}=c_{A}-\frac{1}{2}\left(p_{B}^{R}-c_{B}\right)+\frac{1}{2} \sqrt{4 f t_{A}+\left(p_{B}^{R}-c_{B}\right)^{2}} \\
& N^{R}=\frac{1}{2 f}\left(p_{B}^{R}-c_{B}+\sqrt{4 f t_{A}+\left(p_{B}^{R}-c_{B}\right)^{2}}\right) .
\end{aligned}
$$

The derivative of the price of good A with respect to the regulated price of good B is

$$
\frac{d p_{A}}{d p_{B}^{R}}=\frac{p_{B}^{R}-c_{B}}{2 \sqrt{4 f t_{A}+\left(p_{B}^{R}-c_{B}\right)^{2}}}-\frac{1}{2} .
$$

It is easy to verify that this derivative is always negative: the price of the unregulated good always rises due to the exit of firms induced by the downwards regulation of $p_{B}$. If we evaluate this derivative at the original equilibrium price $p_{B}^{*}$ and number of firms $N^{*}$ after some algebraic manipulation we obtain

(4) $\left.\frac{d p_{A}}{d p_{B}^{R}}\right|_{p_{B}^{R}=p_{B}^{*}}=-\frac{t_{A}}{2 t_{A}+t_{B}}=-\frac{1}{2+\sigma}$,

where $\sigma=t_{B} / t_{A}$ measures the relative strength of product differentiation for good B versus good A.

Equation (4) gives the rate of pass-through of the regulated price into the unregulated price in the circular city model with a zero profit constraint, for small changes in the regulated price away from its unregulated equilibrium value. The maximum rate of pass-

\footnotetext{
${ }^{10}$ See, for example, section 7.1.2 of Tirole (1988).
} 
through in this model is (negative) one half, meaning that at most half of the reduction in the price of good $\mathrm{B}$ will be passed through into a higher price for good $\mathrm{A}$. The maximum pass-through is approached as the market for good $\mathrm{B}$ becomes very competitive ( $t_{B}$ gets close to zero) or the market for good A becomes very uncompetitive ( $t_{A}$ gets very large).

In some markets, the assumption of free entry and exit leading to zero profits may be unrealistic. Without this assumption, a waterbed effect can still be generated by the existence of fixed and common costs if a monopolist is subject to a "global price cap" regulation across all prices. With appropriate choice of the cap, it can be shown that the firm will set second-best "Ramsey" prices that maximize consumer welfare subject to the constraint that firms break even (Laffont and Tirole, 1996, 2000). In the simple case of independent demands and constant marginal costs, these prices satisfy $\left(p_{i}-c_{i}\right) / p_{i}=\theta / e_{i}$ where $c_{i}$ is the marginal cost of good $i, \theta<1$ is a constant and $e_{i}$ is the price elasticity of demand for good $i .^{11}$

If a global price cap is then combined with a further specific regulation of one of the prices, it is straightforward to see that the price of the unregulated good(s) must rise under Ramsey pricing. Intuitively, downwards regulation of the price of one good reduces the variable profit from that good that contributes to covering the common fixed cost. To ensure recovery of the fixed cost, the price(s) of the other good(s) must rise. This will occur so long as the required increase in the unregulated price(s) does not cause them to exceed their monopoly levels, since once a price equals the monopoly level no further increase in variable profit can be achieved.

Mathematically, with two goods, a zero profit constraint implies that $\left(p_{A}-c_{A}\right) q_{A}\left(p_{A}\right)+\left(p_{B}-c_{B}\right) q_{B}\left(p_{B}\right)=f$ where $f$ is the common fixed cost and assuming constant marginal costs for simplicity. If $p_{B}$ is set by regulation then implicit differentiation gives

$$
\frac{d p_{A}}{d p_{B}}=-\frac{q_{B}+\left(p_{B}-c_{B}\right) q_{B}^{\prime}}{q_{A}+\left(p_{A}-c_{A}\right) q_{A}^{\prime}} .
$$

That is, the rate of change of $p_{A}$ in response to $p_{B}$ is the negative of the ratio of the rates of change of variable profit from good $\mathrm{B}$ to variable profit from good A. Provided that $p_{A}$ and $p_{B}$ are both below their monopoly levels, both the numerator and denominator of this fraction are positive, thus $p_{A}$ rises when $p_{B}$ falls.

\subsection{Nonlinear pricing}

The previous discussion assumed linear prices were set for two separate products. Many types of nonlinear pricing are used by firms, including two-part tariffs, declining-block tariffs and quantity discounts. As with demand interdependence, a firm will maximize profits by choosing all the prices in the nonlinear schedule jointly. Thus, in general, if one price in a nonlinear pricing schedule is regulated, it will affect the profit-maximizing values of the other price(s).

\footnotetext{
${ }^{11}$ See for example section 2.2.1 of Laffont and Tirole (2000).
} 
To illustrate, consider two-part pricing by a monopoly that charges a fixed subscription fee of $s$ and a variable usage charge $p$. Suppose that a consumer's net utility from using the monopolist's service takes the form

$$
U=v_{0}+u(q)-s-p q
$$

where $v_{0}$ is a fixed benefit from using the service and $u(q)$ is the utility from using $q$ units. Suppose that $v_{0}$ differs across consumers according to some continuous probability distribution with cumulative distribution $F$. Given the prices, consumers will choose $q$ to maximise $u(q)-p q$, yielding per-consumer demand $q(p)$ and indirect utility $v(p)$. The demand for the service is therefore $D(s, p)=1-F(s-v(p))$.

Assuming a constant marginal cost of usage $c$, the monopolist's profit is

$$
\pi(s, p)=(s+(p-c) q(p)) D(s, p)
$$

Defining $r=s+(p-c) q(p)$ as the profit per customer, $h=(1-F) / F^{\prime}$ as the inverse hazard rate, $e=-p q^{\prime}(p) / q(p)$ as the demand elasticity and $L=(p-c) / p$ as the Lerner index for usage, it is straightforward to verify that the first-order conditions $\partial \pi / \partial s=0$ and $\partial \pi / \partial p=0$ can be written as

$$
h-r=0
$$

and

(6) $h(1-e L)-r=0$

respectively. These conditions indicate that the profit-maximizing levels of $s$ and $p$ are interdependent: the level of $p$ affects profit per customer and consumers' indirect utility, hence affects demand and the size of the marginal effect of $s$ on profits. Similarly, the level of $s$ affects the number of subscribers at any given $p$, hence affects the size of the marginal effect of $p$ on profits. Regulation of either one will affect the monopolist's choice of the other.

In this model, since consumers are identical with respect to their demand for usage, (5) and (6) imply that an unregulated monopolist maximizes profit by setting $L=0$, hence $p=c$, and making all profits from subscriptions. In this case, there is little justification for regulating the usage charge. Nevertheless, (5) shows that a regulated reduction in $p$ will cause an increase in the profit-maximizing value of the subscription fee: at any given value of $s$, profit per customer falls and $h$ increases under the standard increasing hazard rate (decreasing inverse hazard rate) assumption. Profit-maximization requires that this be offset by an increase in $s$ to raise profit per customer and reduce $h$. Intuitively, lower $p$ 
means each customer is less valuable, but demand $D(s, p)$ increases for any given $s$, and the slope of demand $\partial D / \partial s$ may also change. Overall the positive effect of higher demand for subscriptions on profits outweighs the loss in profits from usage and the firm responds by increasing the subscription price.

Since the profit-maximizing usage charge equals marginal cost, the more interesting case is regulation of the subscription charge. If $s$ is regulated downwards from the profitmaximizing level, (6) shows that the monopoly will increase the level of $p$ above cost. Downwards regulation of $s$ reduces profits per customer and increases $h$. Profit maximization requires that this be offset by an increase in $p$ which increases profits per customer, reduces $h$ and increases usage demand elasticity and the Lerner index (so $1-e L$ falls). Again, downwards regulation of $s$ increases the number of subscribers, hence profits from usage at any given $p$, but reduces subscription revenue and may affect $\partial D / \partial p$. Under our assumptions the positive effects on usage profits outweigh the negative effects on subscription profits and the firm responds by raising the usage price.

\section{Applications and discussion}

If at least one of the conditions identified above is met then there are a number of potential implications of the existence of a waterbed effect for regulation. This section discusses some implications for market definition, welfare analysis of regulation, quality provision and price fixing, as well as specific applications to fixed-to-mobile termination, bank overcharges and two-sided markets. This section concludes with a discussion of how to measure the size of a waterbed effect.

\subsection{Market definition}

In antitrust cases or regulatory proceedings, market definition is fundamental to any subsequent analysis. Market definition is often based on the degree of substitutability between the good provided by a candidate market definition and other goods that are or could be supplied. To implement this, the so-called "small but significant non-transitory increase in price” (SSNIP) test has become popular. ${ }^{12}$ This test starts with a very narrow market definition and asks whether a hypothetical monopolist of this market could profitably raise price by a small amount (typically five or ten percent) above the competitive level and maintain this price increase in the long run. If many good substitutes currently exist or could potentially be supplied easily by existing firms then such an increase in price would not be profitable, and the market definition is judged to be too narrow. The test proceeds by successively broadening the market definition until a SSNIP is profitable. The market is said defined to be the narrowest definition at which the SSNIP is profitable.

If a waterbed effect exists, the prices charged by a multiproduct firm are not independent. In such a situation, it is crucial that this interdependence be taken into account to perform market definition correctly. To illustrate, consider the case of cost interdependence discussed in section 2.1 and suppose the firm's total cost function is $C\left(q_{A}, q_{B}\right)=c\left(q_{A}+q_{B}\right)+\psi q_{A} q_{B}$. Suppose also that demands are linear and are given by

\footnotetext{
${ }^{12}$ See, for example, Motta (2004, chapter 3).
} 
$q_{A}=1-p_{A}$ and $q_{B}=1-p_{B}$. In this case, it is straightforward to verify that the perfectly competitive prices, which equal marginal costs, are given by $p_{A}=p_{B}=(c+\psi) /(1+\psi)$. In the context of the SSNIP test, these are the competitive prices against which the hypothetical increase in price should be compared. Now suppose that the cost complementarities are ignored, and a marginal cost benchmark of $c$ is used instead. If there are economies of scope $(\psi<0)$ then $(c+\psi) /(1+\psi)<c$. In this case, the benchmark of $c$ is too high and we are more likely to find that a SSNIP is unprofitable when in fact it may be profitable. Therefore, ignoring economies of scope is likely to lead to a market definition that is too broad. Similarly, ignoring diseconomies of scope $(\psi>0)$ is likely to result in a market definition that is too narrow.

Alternatively, suppose that the competitive price of $(c+\psi) /(1+\psi)$ is correctly identified as the benchmark, but the prices for the two goods are considered in isolation. Section 2.1 showed that with economies of scope when the price of one good is decreased then a profit-maximizing firm will simultaneously decrease the price of the other good. This must be taken into account when conducting the SSNIP test. It is conceivable that a SSNIP of good A that appears profitable on its own becomes unprofitable once the corresponding decrease in the price of good B is taken into account. In this case, a market definition that is too narrow is likely to result. Similar issues in terms of market definition arise in the case of demand interdependence. The main lesson here is that the presence a waterbed effect means that a market definition analysis which does not take these effects into account is likely to be incorrect.

\subsection{Welfare analysis of regulation}

It is common for regulators to perform a quantitative welfare or cost-benefit analysis of a proposed regulation to verify that it is beneficial overall. The basic implication of the existence of a waterbed effect for any such analysis is straightforward: the analysis must take account of the effects in all markets where prices change after regulation. That is, as well as calculating welfare effects in the market for the good with the regulated price, the effects on the price(s) charged for any other good(s) produced by the regulated firms must also be estimated and translated into welfare effects.

In general, downwards regulation of a price will generate welfare benefits if the unregulated price is above marginal cost. However, if the regulated firms are multiproduct firms, the waterbed effect may cause other prices to rise, which may cause welfare losses and welfare transfers. Depending on the rate at which reductions in the regulated price are passed through into increases in other prices and depending on the shape of the demand and cost curves in these markets, such welfare losses may represent a very large fraction of, or even exceed, any benefits in the market that is regulated. Ignoring these effects is likely to result in a cost-benefit analysis that supports regulation when it may not be justified by a complete analysis.

For example, in the New Zealand Commerce Commission's draft report on regulation of fixed-to-mobile termination rates, it ruled out the existence of a waterbed effect whereby a regulated reduction in fixed-to-mobile termination rates would lead to mobile operators increasing other prices such as those for mobile subscription or origination. The Commission initially believed that a waterbed effect could only operate in the presence of a zero-profit constraint, and it did not consider there was adequate evidence that the New 
Zealand mobile telecommunications market was so constrained. ${ }^{13}$ The Commission therefore confined its quantitative analysis of its proposed downwards regulation of fixedto-mobile termination rates to the fixed-to-mobile call origination market and ignored any effects arising from price changes in the mobile market.

The Commission was subsequently convinced that a waterbed effect would operate even absent a zero-profit constraint, following arguments that are discussed below. In its final report, the Commission modified its quantitative analysis and attempted to estimate the price increases that would occur in the mobile market and the resulting effects on mobile consumers and producers, and subtracted any detriments in the mobile market from the estimated benefits in the fixed-to-mobile market. ${ }^{14}$ It is difficult to isolate the impact of this change on the Commission's quantitative analysis because many other inputs and assumptions were also changed simultaneously. However, substantial negative effects were estimated to occur in the mobile market, which weakened the case for regulation.

\subsection{Provision of quality}

This paper has focused on prices as the strategic variable of firms. In reality, the products supplied by firms have more dimensions, including quality. Thus, even a single product firm using linear pricing may, in fact, be optimising over multiple variables. Alternatively, firms may sell varieties of essentially the same product that have different qualities or different levels of associated services such as after-sales support. In these cases, regulation of a price may affect the marginal benefits and costs of the other variables, which may or may not be desirable to the regulator.

It is not possible to make precise theoretical predictions about the effects of price regulation on provision of quality or variety of products. At a given price, a firm will choose the quality level at which the benefits from a marginal increase in quality equal the cost of providing that marginal increase in quality. In the case of unit demand per consumer, for example, the marginal benefit depends on the willingness to pay for quality of the consumer who is just indifferent between buying the firm's product or not. A regulated price reduction will increase the quantity of goods that the firm sells, and change the identity of the marginal consumer. Presumably, the marginal cost of quality is increasing in the quantity sold, but the willingness to pay for quality of the marginal consumer may increase or decrease, depending on consumer preferences. Thus, a regulated price reduction may cause either an increase or decrease in the quality chosen by the firm.

In addition, it can be shown that firms can either over- or under-provide quality or variety of products relative to what a social planner would choose, depending on the form of consumers' preferences and the costs of quality or diversity. ${ }^{15}$ Thus, whether the quality change in response to a regulated price reduction is beneficial from a welfare point of view is also uncertain. Nevertheless, the general point remains that it may not be appropriate to assess the effects of price regulation in terms of changes in the market quantity alone. If regulation causes a change in the quality level of products that are supplied, this will affect consumer welfare alongside the price decrease, and this should be taken into account in quantitative analysis.

\footnotetext{
${ }^{13}$ New Zealand Commerce Commission, Schedule 3 Investigation into Regulation of Mobile Termination, Draft Report, 18 October 2004, public version, paragraph 340.

${ }^{14}$ New Zealand Commerce Commission, Schedule 3 Investigation into Regulation of Mobile Termination, Final Report, 9 June 2005, public version, from paragraph 537.

${ }^{15}$ See, for example, Tirole (1988, section 2.2).
} 


\subsection{Price fixing}

The existence of a waterbed effect also has implications for collusion among multiproduct firms. Aside from the issue of how multi-market contact can facilitate collusion (Bernheim and Whinston, 1990), interdependence between two products affects the incentives to collude on the price of either one. Obviously, firms will be better off if they can collude in both markets at the same time. However, market characteristics may make collusion more likely in one market compared to the other. For example, one market may have many firms, making it difficult to sustain a collusive equilibrium, while the other market has few. It is therefore useful to examine the implications of the linkages between the two markets on incentives to collude in one market.

Suppose for example that two firms each produce goods A and B. In terms of either good, the outputs of the two firms are substitutes, but suppose that A and B are complements in demand. Now suppose that the firms collude on the price of good A. This will raise prices and profit in the A market, since the firms' products are substitutes in that market. However, a higher price for A will lead to a reduction in demand for good B, since the two goods are complements. Lower demand for B will cause the firms to cut prices in that market, and profits in the B market will fall, offsetting some of the gains from collusion in market A. The fact that A and B are complements also affects a firm's incentives to defect from a collusive arrangement. If one firm does, it will undercut the collusive price in market $\mathrm{A}$. This will increase demand in market $\mathrm{B}$, and raise the gains from defection.

Therefore, if the two goods are complements, gains from collusion are lower and the incentive to defect from a collusive arrangement is higher than if the two goods were independent. This will generally make collusion more difficult to sustain in either market. On the other hand, if the two goods are substitutes, collusion becomes easier to sustain. In that case, collusion in the market for A will raise demand in the B market, which increases the benefits from collusion, while defecting in the A market will reduce demand in the B market, which makes defecting less attractive. Similar effects occur with nonlinear pricing. Suppose firms produce a single product but charge a two-part tariff. Collusion in usage fees will raise these prices and make attracting an additional customer more profitable. However, the increased gain from attracting customers will make competition for customers more intense, which will lead to some or all of the gains from collusion being competed away through lower fixed fees.

The fact that some of the effects of collusion may be undone through linkages across markets does not mean that we should not be concerned about collusion in these cases. For example, if the two goods are complements, higher prices from collusion in one market leads to lower prices in the other market, and the net effect on the average price across the two markets may be small. Nevertheless, the relative prices across the two markets may still be of concern from a welfare point of view. Depending on consumer preferences, a high price in one market and a low price in the other market may imply a lower welfare level than if the average of these two prices applied in both markets.

\subsection{Fixed-to-mobile termination and bank charges}

A mobile network sells call termination services to fixed-line networks (and other networks) and mobile telephony services to mobile customers. A bank sells a bundle of account services together with penalty fees for unauthorized overdrafts, with separate 
prices for each. In both cases, the demands for the products are interdependent and a waterbed effect will arise from regulation.

To illustrate, suppose that a mobile firm produces only mobile subscriptions and fixedto-mobile termination. Let $p_{A}$ be the subscription price and let $p_{B}$ be the per-minute termination rate. This termination rate is charged to fixed-line firms which sell fixed-tomobile services to fixed-line consumers. For simplicity, assume that the fixed-line firms are perfectly competitive and there are no other costs of producing fixed-to-mobile calls aside from the mobile termination rate. Then the fixed-to-mobile retail price is simply $p_{B}$ per minute. In this example, $q_{A}\left(p_{A}\right)$ is the demand for mobile subscriptions. Let $q_{B}\left(p_{B}\right)$ be the demand for fixed-to-mobile calls per mobile subscriber. Then the total demand for mobile termination is $q_{A}\left(p_{A}\right) q_{B}\left(p_{B}\right)$ and this depends on the price charged for mobile subscription. However, the demand for mobile subscription does not depend on the termination price, assuming that mobile subscribers do not care about incoming calls.

Assume further that producing a mobile subscription has a constant marginal cost of $c$, and that mobile termination is costless to provide. Then a monopoly mobile operator's profit is

$$
\pi\left(p_{A}, p_{B}\right)=\left[p_{A}-c+q_{B}\left(p_{B}\right) p_{B}\right] q_{A}\left(p_{A}\right)
$$

That is, each mobile subscriber generates subscription profits of $p_{A}-c$ and termination revenues of $q_{B}\left(p_{B}\right) p_{B}$. Note that the termination revenues are equivalent to a negative persubscriber fixed cost and the marginal revenue from subscriptions, $q_{A}\left(p_{A}\right)+\left[p_{A}+q_{B}\left(p_{B}\right) p_{B}\right] q_{A}^{\prime}\left(p_{A}\right)$, depends on the termination rate $p_{B}$. Thus, a waterbed effect will exist if the termination rate is changed by regulation. Under regulation the firstorder condition $\partial \pi / \partial p_{A}=0$ defines the profit-maximizing subscription price $p_{A}\left(p_{B}\right)$. Implicit differentiation gives

$$
\frac{d p_{A}}{d p_{B}}=\frac{\left(q_{B}+q_{B}^{\prime} p_{B}\right) q_{A}^{\prime}}{2 q_{A}^{\prime}+\left(p_{A}-c+q_{B} p_{B}\right) q_{A}^{\prime \prime}} .
$$

The denominator is negative by the second-order condition for $p_{A}$. The term in brackets in the numerator is the marginal termination revenue per mobile subscriber, which equals marginal termination profit since there are no termination costs. A monopolist would set this term to zero to maximize termination profits. Thus, provided that the regulated termination rate is below the monopoly termination rate, the term in brackets in the numerator will be negative, hence $d p_{A} / d p_{B}<0$ since $q_{A}^{\prime}<0$. This shows that downwards regulation of the mobile termination rate causes prices charged to mobile subscribers to rise. The basic mechanism at work is simple: a reduction in the termination rate causes the marginal revenue per mobile subscriber to fall at all subscription levels, which causes the profit-maximizing subscription fee to rise.

In fact, a waterbed effect exists even if the mobile market is perfectly competitive. This results in a "competitive bottleneck" (Wright, 2002 and Armstrong and Wright, 2008) where although mobile firms compete intensely for subscribers, each has a monopoly over 
terminating fixed-line calls to its own subscribers. In this case, competition will drive the mobile subscription price down to the per-customer marginal cost. Since each mobile subscriber brings termination revenues of $q_{B}\left(p_{B}\right) p_{B}$, perfect competition gives $p_{A}=c-q_{B}\left(p_{B}\right) p_{B}$, so mobile subscribers receive a subsidy equal to the termination revenues that they generate. Clearly, any reduction in the termination rate that reduces termination revenues will increase the subscription price.

A similar mechanism is at work in the case of bank overcharges mentioned in the introduction. Banks sell a bundle of account services together with penalty fees for unauthorized overdrafts, with separate prices for each. Regulation of overcharge fees reduces the (expected) profit per customer, which affects the incentives of banks to attract customers, therefore will affect the level of other prices set by banks such as monthly account fees. To illustrate briefly, suppose banks provide only accounts and unauthorized overdraft services. Since almost everyone has a bank account, banks compete with other banks, and banks are horizontally differentiated or there are switching costs, a Hotelling type model is appropriate for the market. In particular, suppose that a consumer located at $x \in[0,1]$ gets the following utility from joining bank $i=1,2$ :

$$
u_{i}=v+u(q)-t_{i}(x)-p_{A i}-p_{B i} q
$$

where $v$ is the fixed benefit from having an account, $u(q)$ is the utility from overdrawing by $q, t_{i}(x)$ is the "transportation" cost of joining bank $i, p_{A i}$ is the account fee, and $p_{B i}$ is the per-unit overdraft penalty. In the linear Hotelling model, $t_{1}(x)=t x$ and $t_{2}(x)=t(1-x)$ where $t$ measures the degree of horizontal differentiation.

Consumers who join bank $i$ choose $q$ to maximize $u(q)-p_{B i} q$ giving demand for overdrafts of $q\left(p_{B i}\right)$ and indirect utility to consumers of $v\left(p_{B i}\right)$. Assuming that $v$ is large enough so the market is covered, bank $i$ 's market share is

$$
s_{i}=\frac{1}{2}+\frac{1}{2 t}\left[v\left(p_{B i}\right)-p_{A i}-\left(v\left(p_{B j}\right)-p_{A j}\right)\right]
$$

Suppose bank $i$ 's profit is

$$
\pi_{i}=\left(p_{A i}-f+\left(p_{B i}-c\right) q\left(p_{B i}\right)\right) s_{i}
$$

where $f$ is a per-customer cost and $c$ is the marginal cost of overdrawn funds. Suppose also that $p_{B}$ is the same for both banks. Then, it is straightforward to verify that the equilibrium account fees are

$$
p_{A i}=f+t-\left(p_{B}-c\right) q\left(p_{B}\right)
$$


for $i=1,2$. Thus equilibrium account fees are decreasing in the per-customer profit from overdraft penalties. If $p_{B}$ is set by regulation and this reduces the per-customer profit from penalties, account fees will rise accordingly. Intuitively, lower profit from penalties reduces the attractiveness of a marginal customer to the banks. They therefore compete less aggressively in account fees, and these fees rise in response to the regulation. ${ }^{16}$

\subsection{Regulation of two-sided markets}

A firm in a two-sided market serves two distinct groups of consumer and creates value by providing a "platform" that facilitates some form of interaction, such as trade or communication, between the two groups. A key characteristic of such markets is that the volume of interactions on a platform, hence its potential value, depends on the structure of the prices charged to the two sides of the market. That is, the volume of interactions will change if the price charged to one side is reduced while the price charged to the other side is increased by the same amount.

Examples of two-sided markets include videogame platforms, document publishing software such as Adobe Acrobat, credit cards, matching services such as dating agencies and real-estate agents, and so on. The basic economic characteristics of such markets have been examined by Armstrong (2006), Caillaud and Jullien (2003), and Rochet and Tirole (2003, 2006). These authors have shown that a firm that operates a two-sided platform must maximize its profits by choosing the prices charged to both sides in conjunction. That is, it must consider the structure of prices, as well as the overall price level. Clearly, then, regulation of one of the prices in a two-sided market must take account of the effect on the price charged on the unregulated side of the market.

In terms of the causes of a waterbed effect discussed previously, two-sided markets can exhibit both cost and demand interdependence. If, for example, the platform incurs a cost for each interaction that takes place between consumers, and if the number of interactions depends on the numbers of both types of consumer that use the platform, then variable costs are jointly determined by demands on both sides of the market. Similarly, if consumers on each side of the market derive a greater benefit from using the platform if there are a greater number of consumers on the other side of the market using the same platform, then there is demand interdependence. Models of two-sided markets often assume both of these features.

To illustrate, consider a simple model of a monopoly two-sided platform introduced by Rochet and Tirole (2003). If we let $p_{A}$ and $p_{B}$ represent the prices charged to the two sides of the market then the monopolist's profit is given by

$$
\pi\left(p_{A}, p_{B}\right)=\left(p_{A}+p_{B}-c\right) q_{A}\left(p_{A}\right) q_{B}\left(p_{B}\right)
$$

where $q_{A}\left(p_{A}\right)$ and $q_{B}\left(p_{B}\right)$ are the "quasi-demands" on the two sides of the market. That is, $q_{A}\left(p_{A}\right)$ is the volume of interactions on the platform that "A-side" consumers are willing to make with "B-side" consumers at a price of $p_{A}$ per interaction and similarly for

\footnotetext{
${ }^{16}$ Nevertheless, in this model, consumer surplus and welfare are maximised for $p_{B}=c$, thus the existence of a waterbed effect does not completely undermine the case for regulation of overcharge fees.
} 
$q_{B}\left(p_{B}\right)$. In this model, the firm earns revenue of $p_{A}+p_{B}$ and incurs a cost of $c$ per interaction that occurs on its platform. The total number of interactions is given by the product of the demands on the two sides of the market, that is, all potential interactions are assumed to occur.

The first-order condition for $p_{A}$ is

(7) $\frac{\partial \pi}{\partial p_{A}}=q_{A} q_{B}+\left(p_{A}+p_{B}-c\right) q_{A}^{\prime} q_{B}=0$

If $p_{B}$ is fixed by regulation then this implicitly defines $p_{A}$ as a function of $p_{B}$. Note that for any given level of $p_{B}$, regulation results in the "one-sided" monopoly price for good A. That is, when setting the price of good A under regulation of the price of good B, the firm will ignore the interdependence of the demands on the two sides of the market, and set the price for good A that maximizes the profit taking the price of good B as given. Dividing (7) by $q_{B}$, implicit differentiation gives

$$
\frac{d p_{A}}{d p_{B}}=-\frac{q_{A}^{\prime}}{2 q_{A}^{\prime}+\left(p_{A}+p_{B}-c\right) q_{A}^{\prime \prime}} .
$$

As usual, the denominator is negative by the second-order condition, thus since $q_{A}^{\prime}<0$, the price of good A increases when the price of B is regulated downwards.

Alternatively, Armstrong (2006) and Armstrong and Wright (2007) consider competition among two-sided platforms that charge subscription fees rather than perinteraction fees. In the simplest version of their model, there are two platforms and all consumers join one platform or the other but not both. The platforms are differentiated according to the Hotelling model with the platforms located at the ends of the unit interval, and linear transportation costs. In their model, the equilibrium number of consumers of type $i=A, B$ on platform $k=1,2$ is given by

$$
n_{i}^{k}=\frac{b_{i}\left(p_{j}^{l}-p_{j}^{k}\right)+t_{j}\left(p_{i}^{l}-p_{i}^{k}\right)}{2\left(t_{i} t_{j}-b_{i} b_{j}\right)} \text { fori } \neq j=A, B \text { and } k \neq l=1,2
$$

where $p_{i}^{k}$ is the subscription fee charged by platform $k$ to consumers of type $i, t_{i}$ is the "transportation cost" parameter of type $i$ consumers and $b_{i}$ is the marginal network benefit that a type $i$ consumer gets when the number of consumers of the other type using the same platform increases. Assuming costs of $f_{i}$ per type $i$ customer, firm $k$ 's profit function is

$$
\pi^{k}=\left(p_{A}^{k}-f_{A}\right) n_{A}^{k}+\left(p_{B}^{k}-f_{B}\right) n_{B}^{k}
$$


Let us suppose that the price charged to B-types is regulated to $p_{B}$ for both firms. In this model, Armstrong (2006, equation 10) shows that, in a symmetric equilibrium, the price charged to A-types is

$$
p_{A}^{*}=f_{A}+t_{A}-\frac{b_{B}}{t_{B}}\left(p_{B}-f_{B}+b_{A}\right)
$$

Therefore, we have $d p_{A}^{*} / d p_{B}=-b_{B} / t_{B}<0$, and so downwards regulation of the price charged to B-types causes the equilibrium price charged to A-types to rise. Intuitively, equation (8) can be interpreted as saying that the price charged to A-types is equal to the normal Hotelling equilibrium price $\left(f_{A}+t_{A}\right)$ minus the opportunity cost of raising the Atype price by enough that one A-type consumer leaves the platform. The last term in (8) is that opportunity cost because when the number of A-types on the platform decreases by one, the number of B-types also decreases by $b_{B} / t_{B}$, and each B-type consumer generates a profit of $p_{B}-f_{B}$ and confers external benefits on A-types of $b_{A}$. Thus, downwards regulation of the price charged to B-types reduces the opportunity cost of raising the Atype price, so $p_{A}$ increases in equilibrium.

The above examples have demonstrated that downwards regulation of the price on one side of a two-sided market causes the profit-maximizing price charged on the other side of the market to rise. This reflects a more general principle that in a two-sided market, it does not make sense to consider the price on one side of the market in isolation from the price on the other side. ${ }^{17}$ Rather than the individual price charged to either side, it is the price level, $p_{A}+p_{B}$, and the price structure (for example, as represented by the fraction $\left.p_{A} /\left(p_{A}+p_{B}\right)\right)$ that matter for welfare and profit-maximization. Therefore, in a two-sided market, it is risky to simply regulate the price charged on one side of the market to marginal cost, or even to regulate the prices charged on both sides to marginal cost. As Rochet and Tirole (2003) have shown, the optimal (second-best) prices generally require that the price level equal the total marginal cost on both sides, while the price structure must take account of differences in the demands on each side and the cross-platform network benefits. In general, this is a more complex problem than regulating a one-sided market, as a regulator must be informed about demand as well as costs.

\subsection{Measuring the size of a waterbed effect}

The main reason for being interested in the waterbed effect is that its existence implies that beneficial downwards regulation of one price can lead to increases in other prices that can cause losses offsetting the benefits of regulation. ${ }^{18}$ It is therefore useful to know how to measure the size of this effect. If a multiproduct firm sets two independent prices, as in most of the examples in this paper, then a simple definition of the size of the waterbed effect is the increase in the unregulated price divided by the size of the decrease in the

\footnotetext{
${ }^{17}$ See Wright (2004) for a discussion of a number of issues that can arise from applying "one-sided thinking” in two-sided markets.

${ }^{18}$ As was shown, in some cases a regulated decrease of one price could lead to decreases in other prices. The existence of a waterbed effect is less likely to be of concern in this type of situation, so I do not consider it here.
} 
regulated price. This definition applies also to two-sided markets where the firm sets simple linear subscription or usage fees on both sides of the market. However, this measure by itself does not give information about how many consumers are affected by the waterbed effect, nor the size of the impact on them.

If firms uses complex nonlinear pricing or sell more than two products, then the overall size of the waterbed effect is more difficult to define. In this case, one way to define the size of the effect is in terms of firms' profits, since profit is a single measure that can be calculated regardless of what type of pricing is used. Let $\pi_{0}$ be a firm's profit before regulation, $\pi_{1}$ be its profit after regulation and after it has adjusted all prices, and let $\pi_{2}$ be its profit after regulation but with all unregulated prices held at their pre-regulation levels, where $\pi_{0} \geq \pi_{1}>\pi_{2}$ in most cases. Then the size of the waterbed effect can be defined as $\left(\pi_{1}-\pi_{2}\right) /\left(\pi_{0}-\pi_{2}\right)$ : the fraction of lost profit due to regulation that is offset due to adjustment of the non-regulated prices. ${ }^{19}$ In general, greater values of $\pi_{1}-\pi_{2}$ will require larger changes of the unregulated prices, everything else equal, so a higher value of this statistic can be interpreted as a stronger waterbed effect. The advantage of this definition is that it can be calculated regardless of how many products the firm sells or what type of pricing it uses. The disadvantage is that $\pi_{2}$ is not generally observed. In this case, it is still possible to test for a " $100 \%$ " waterbed effect $\left(\pi_{1}=\pi_{0}\right)$ and to say whether the effect is less or greater than $100 \%$, but values other than $100 \%$ cannot be enumerated. One possibility to overcome this problem is to use a calibrated model of the market to simulate $\pi_{2}$, although this may be a complex task. Alternatively, it is possible to approximate $\pi_{2}$ from $\pi_{0}$ if the quantity of the regulated service prior to regulation is known, by subtracting from $\pi_{0}$ the regulated price reduction multiplied by the pre-regulation quantity. If the demand elasticity for the regulated service is known, it could be used to further improve this estimate.

An alternative, if profits cannot be calculated or observed, is to measure the size of the waterbed effect from a consumer's point of view. If the firm sells more than two products to independent consumer groups, then the only natural way to aggregate across the groups and get a single measure of the size of the waterbed effect is the profit-based approach discussed above. However, if the firm uses nonlinear pricing and sells to a single group of consumers, then it is possible to construct a single measure based on consumer expenditure. To illustrate, consider the case of fixed-to-mobile termination. Since mobile firms use complex menus of nonlinear tariffs to sell mobile services to mobile consumers, there is no single price that we can use to measure how downwards regulation of the fixedto-mobile termination rate is passed through to mobile consumers. In addition, mobile consumers are heterogeneous and will have different usage patterns, will select different tariff plans, and will attract different volumes of fixed-to-mobile calls.

To overcome this complexity, we can measure the waterbed effect in terms of its effects on per-customer expenditure. A stronger waterbed effect will necessarily imply that lower termination rates lead to greater expenditure by mobile consumers for a given level of usage. Since termination revenue is like a negative per-customer cost, a natural measure of the waterbed effect is how much of the "cost increase" created by regulation is passed through into higher per-customer expenditure. Let $q$ and $Q$ be a mobile customer's volume of usage and volume of fixed-to-mobile calls received prior to regulation and let

\footnotetext{
${ }^{19}$ This definition is used by Armstrong and Wright (2008) in the context of mobile termination.
} 
$e_{0}(q)$ and $e_{1}(q)$ be the expenditure required to buy a fixed bundle of usage of $q$ before and after regulation respectively. If $a_{0}$ is the unregulated fixed-to-mobile termination rate and $a_{1}<a_{0}$ is the regulated rate, then the size of the waterbed effect can be measured as $\left(e_{1}(q)-e_{0}(q)\right) /\left(\left(a_{0}-a_{1}\right) Q\right)$ : the fraction of lost termination revenues per customer that are passed through to higher expenditure per customer, at a given usage level. Generally, consumers will differ according to their values of $q$ and $Q$, so this measure can be calculated separately for different groups, or averaged across consumers to form a single statistic.

Genakos and Valletti (2007) and Andersson and Hansen (2007) perform empirical tests for the existence of a waterbed effect in mobile telephony. Both perform the type of profit test described above but do not attempt to estimate the unobserved $\pi_{2}$ and simply test whether there is a significant difference between $\pi_{0}$ and $\pi_{1}$, controlling for other factors that may affect profits. Genakos and Valletti find that regulation of fixed-to-mobile termination rates is associated with a small but statistically significant reduction in mobile operators' profits, indicating that the waterbed effect is less than full. Andersson and Hansen find no significant difference in mobile operators' profits before and after regulation, which is evidence of a full waterbed effect. Genakos and Valletti also use a cross-country panel dataset of prices and termination rates to test whether fixed-to-mobile termination rates regulated at low levels are associated with relatively higher prices for other services in the mobile market. Their empirical specification implements the type of expenditure measure described above. Since they lack data on actual usage, exogenous representative usage bundles are imposed. The main finding is that a regulated percentage reduction in fixed-to-mobile termination rates is associated with an almost equal percentage increase in the expenditure necessary to buy a given usage bundle, which is evidence for the existence of a strong waterbed effect.

\section{Conclusion}

This paper has analyzed the conditions that lead to the existence of a waterbed effect, whereby the prices charged by a multiproduct firm are interdependent, and regulation of any one price will cause changes in the other price(s) set by the firm as a result of its profit-maximizing behavior. In general, a waterbed effect will exist if either the marginal revenue or marginal cost of one good depends on the quantity of the other good(s). A waterbed effect may also exist with nonlinear pricing or if competing firms are subject to a zero-profit constraint or global price cap and there is a common fixed cost.

As has been shown, the existence of such effects has important implications for regulatory analysis. First, it affects market definition analysis. Ignoring linkages between prices when attempting market definition may lead to a definition that is either too narrow or too wide. Welfare analysis that ignores a waterbed effect will also be erroneous, as it will not take full account of all the welfare effects of any proposed regulation. The effects may also not be limited to prices, and price regulation can affect other strategic variables such as quality and variety. Waterbed linkages also have implications for the ability of firms to sustain collusion. Finally, two-sided markets are a special kind of market where there may be both demand and cost interdependence. In such markets, it does not make 
sense to consider regulation of only the price charged to one side of the market, and any such regulation runs the risk of reducing rather than increasing welfare.

\section{$5 \quad$ References}

Andersson, K. and B. Hansen (2007) "Network Competition: Empirical Evidence on Termination Rates and Profitability,” Mimeo, Telenor.

Armstrong, M. (2002) “The Theory of Access Pricing and Interconnection,” in M. Cave, S. Majumdar and I. Vogelsang (ed.), Handbook of Telecommunications Economics, NorthHolland: Amsterdam.

Armstrong, M. (2006) “Competition in Two-sided Markets," RAND Journal of Economics, 37: 668-691.

Armstrong, M. and J. Wright (2007) "Two-sided Markets, Competitive Bottlenecks and Eexclusive Contracts,” Economic Theory, 32: 353-380.

Armstrong, M. and J. Wright (2008) "Mobile Call Termination," Mimeo, National University of Singapore.

Bernheim, B. and M. Whinston (1990) "Multimarket Contact and Collusive Behavior," RAND Journal of Economics, 21: 1-26.

Caillaud, B. and B. Jullien (2003) "Chicken \& Egg: Competition among Intermediation Service Providers,” RAND Journal of Economics, 34: 309-328.

Genakos, C. and T. Valletti (2007) “Testing the "Waterbed” Effect in Mobile Telephony," Centre for Economic Performance Discussion Paper, Number 827.

Hausman, J. and G. Leonard (1999) “Efficiencies from the Consumer Viewpoint," George Mason Law Review, 7: 707-727.

Laffont, J.-J. and J. Tirole (1996) "Creating Competition through Interconnection: Theory and Practice,” Journal of Regulatory Economics, 10: 227-256.

Laffont, J.-J. and J. Tirole (2000) Competition in Telecommunications. MIT Press: Cambridge.

Motta, M. (2004) Competition Policy: Theory and Practice. Cambridge University Press.

Rochet, J.-C. and J. Tirole (2003) "Platform Competition in Two-sided Markets," Journal of the European Economic Association, 1: 990-1029.

Rochet, J.-C. and J. Tirole (2006) “Two-sided Markets: A Progress Report,” RAND Journal of Economics, 37: 645-667. 
Salop, S. (1979) "Monopolistic Competition with Outside Goods," Bell Journal of Economics, 10: 141-156.

Tirole, J. (1988) The Theory of Industrial Organization. MIT Press.

Vives, X. (2005) “Games with Strategic Complementarities: New Applications to Industrial Organization,” International Journal of Industrial Organization, 23: 625-637.

Wright, J. (2002) "Access Pricing under Competition: An Application to Cellular Networks,” Journal of Industrial Economics, 50: 289-315.

Wright, J. (2004) “One-sided Logic in Two-sided Markets," Review of Network Economics, 3: 42-63. 